\title{
A pilot assessment of parental practices and attitudes regarding risk disclosure and clinical research involving children in Huntington disease families
}

Leon S. Dure, $M D^{1}$, Kimberly Quaid, $P h D^{2}$, and T. Mark Beasley, $P h D^{3}$

\begin{abstract}
Purpose: To characterize parental practices of informing children of risk for Huntington disease (HD), and to understand the attitudes of parents concerning childhood participation in HD research. Methods: An anonymous Internet survey was accessed by individuals of HD families. The survey probed for data regarding individual risk for $\mathrm{HD}$, as well as when or if children had been informed of the disease. Respondents expressed their attitudes concerning childhood participation in HD clinical research. Results: Two hundred forty-nine individuals responded ( $\sim 80 \%$ female), and $84 \%$ had never participated in an HD clinical trial. Seventy-five percent of respondents were parents; nearly two thirds of them had provided some information about HD to their children. There was overwhelming support for affected, at-risk, and unaffected adults in terms of HD research participation, but there was a statistically significant disparity by gene status, with gene negative and symptomatic gene positive adults being more inclined to participate than at-risk or asymptomatic/gene positive adults. More than $50 \%$ of respondents supported childhood participation, but typically in late adolescence (15-18 years). Gene negative and symptomatic adults were statistically more likely to agree with childhood inclusion than at-risk or asymptomatic/ gene positive adults. Conclusion: These results serve as pilot data for further investigations to address childhood participation in HD research. In addition, these findings will inform ongoing studies as to appropriate practices to undertake to include minors. Genet Med 2008:10(11):811-819.
\end{abstract}

Key Words: Huntington disease, clinical research, childhood participation, genetic epidemiology, informed consent, assent

Huntington disease (HD) is an autosomal dominant disorder characterized by the appearance in midlife of chorea, incoordination, and a gait abnormality. ${ }^{1}$ It is caused by an expanded trinucleotide repeat of cytosine, adenine, and guanine $\left(\mathrm{CAG}_{\mathrm{n}}\right)$ in the Huntington gene on the short arm of chromosome 4 , and affects approximately $4-10$ people per 100,000 of the general population. Because of its somewhat late appearance, individuals who carry the gene for Huntington disease often have already begun their families before the onset of symptoms. The disorder is progressive, with no effective cure. Recent work suggests that there may be a prodrome of behavioral and psychiatric pathologies that antedates the motor syndrome, and this remains an ongoing area of investigation..$^{2-5}$

\footnotetext{
From the ${ }^{1}$ Departments of Pediatrics and Neurology, The University of Alabama at Birmingham School of Medicine, Alabama; ${ }^{2}$ Department of Medical and Molecular Genetics, Indiana University School of Medicine, Indiana; ${ }^{3}$ Department of Biostatistics, School of Public Health, The University of Alabama at Birmingham, Alabama.

Leon S. Dure, MD, 1600 7th Avenue South, 314 CH, Birmingham, AL 35233. E-mail: ldure@peds.uab.edu.

Disclosure: The authors declare no conflict of interest.

Submitted for publication June 7, 2008.

Accepted for publication August 14, 2008.

DOI: 10.1097/GIM.0b013e31818adb01
}

The Huntington Study Group (HSG) is an international organization of clinical investigators dedicated to developing clinical trial initiatives with the stated goal of discovering an effective treatment for the disease. A number of trials have been carried out, yet no clearly effective treatment modalities have been identified. ${ }^{6,7} \mathrm{~A}$ recent initiative undertaken by the HSG is the Cooperative Huntington Observational Research Trial (COHORT), involving sites in the United States, Canada, and Australia. The study objective is "to collect prospective data from individuals who are part of an HD family, in order to relate phenotypes between individuals and families with each other and genetic factors in order to learn more about HD, develop potential treatments for HD, and to plan for future research studies of experimental drugs aimed at slowing or postponing the onset and progression of HD," (I Shoulson et al., personal communication). Inclusion criteria are directed at individuals who have clinically diagnosed Huntington disease, or are at risk for the disorder. First-degree relatives including parents, siblings, and children are eligible for recruitment. In addition, family members with no risk of Huntington disease are encouraged to participate, in an attempt to develop a cohort of unaffected individuals.

As part of the study, individuals will be seen on a regular basis, and at each visit undergo a neurologic examination, as well as an interview regarding family and medical history. Each 
participant will provide a blood specimen, an aliquot of which will be analyzed for CAG repeat length, and the remaining stored in a central facility, a biobank, which will serve as a repository for basic science research. To date, over 1000 individuals have been enrolled.

During the planning stages for this study up to the present time, there have been a number of discussions revolving around the enrollment of minor children. Currently, only symptomatic children have been enrolled, but there is a scientific basis to encourage the participation of unaffected and atrisk minors. This includes the fact that Huntington disease is in all likelihood a disorder with a definable phenotype that predates the appearance of motor symptomatology. ${ }^{2,4,5,8}$ In addition, it is as yet unclear as to why individuals with identical mutations may have quite variable ages of onset. These variations are felt to be due to either other genetic or environmental factors. Because it is reasonable to suppose that interventional trials would have the most impact earlier in the course of the disease, thorough and early characterization of individuals is warranted. Thus, the inclusion of minor children in COHORT may not only help to illuminate early signs of HD, but also assist in understanding what at some point may be a distinct study population.

Despite the intent to include children, there have been concerns raised regarding the processes of enrollment, particularly the issue of consent. Although parents may be considered as a proxy for a child's participation in clinical research, there is a consensus that assent of a child should be obtained if that child is to participate in clinical research, ${ }^{9-11}$ and US federal regulations require such assent. ${ }^{12}$ Although the provision for childhood assent is currently in widespread use in a variety of clinical trial initiatives, the application is somewhat problematic for Huntington disease. One reason for this relates to the fact that before the recruitment of a child into an HD study such as COHORT, the child must know why he/she is eligible for inclusion. Currently, little is known how HD families process information regarding risk, making it difficult to assess a likely age at which a child would be capable of assent. In addition, there are concerns regarding the disposition of biobank material, specifically relating to confidentiality and the determination of the presence or absence of the HD mutation. ${ }^{13}$ Parental attitudes toward participation are not currently known, nor is there a good understanding of when children in HD families learn of their risk for disease. Finally, the impact of participation by children remains an open question. Clearly, these issues will need to be resolved to satisfy both regulatory and social concerns regarding the participation of children in a clinical research project such as COHORT.

With the support of the COHORT Steering Committee, two study investigators (authors L.S.D. and K.Q.) where charged with exploration of the issues and potential problems related to childhood enrollment in the study. One strategy which has been employed to illuminate potential issues for clinical trialists has been that of an "ethical pilot study." This method relies upon ethnographic techniques to assess parental attitudes regarding study activities, thus informing investigators of how the activities in a particular study may be received by potential participants. In a study of parental attitudes regarding childhood participation in a genetic study of hearing loss, Gillam et al. ${ }^{14}$ were able to illustrate particular issues relating to genetic literacy and competence of parents, as well as to identify attitudes affecting consent. While serving to provide some insight into how a particular clinical trial may need to be structured for the inclusion of children, we have adopted a modification of this type of effort to access parental attitudes regarding childhood participation in HD clinical research. Using an anonymous Internet survey structured in such a way as to obtain basic demographic and historical information, we have derived pilot data regarding parental practices of informing their children of the presence of HD in the family. Our results suggest a variety of mechanisms with which COHORT may be adapted to ethically enroll minors, and to be sensitive to parental attitudes regarding juvenile inclusion. In addition, this pilot has also prompted a number of other investigations which will be necessary to fully capture juvenile participation in HD clinical research. Indeed, this mechanism could serve as a template for other genetic observational studies.

\section{METHODS}

The Internet survey was created on Survey Monkey (www. surveymonkey.com), and was reviewed and approved by the Institutional Review Board of the University of Alabama at Birmingham. The survey was linked to two Web sites, that of the Huntington Disease Society of America (HDSA) and the HSG. The link was active from May 2007 to October 2007 (150 days). No respondents were included in the data set after that time, when the links were removed.

Consent for participation was implied by completion of the survey. Other than gender, age, and HD-related information, no personal information was obtained. There were 251 respondents to the survey. Periodic review of completed surveys was performed by one of the authors (LSD) to gauge activity and response totals. Upon completion of data collection, the dataset was downloaded from the survey site in a spreadsheet format for review and analysis.

The survey was designed in multiple parts. There was no attempt to force completion of any particular question in the survey. However, upon completion of certain questions, the survey would direct the respondent to a particular set of questions (see Fig. 1). The first portion collected basic demographic information including age, gender, general region of residence, education, HD status, history of participation in HD-related clinical trials, and if the respondent had any children at risk for HD. If the respondent indicated that they had children at-risk, the survey was directed to a series of questions regarding age of their children, the risk status of their children, and whether or not the children had been informed of HD. Respondents indicating no at-risk children were directed to a final series of questions probing attitudes regarding participation of adults and children in clinical research of HD. 


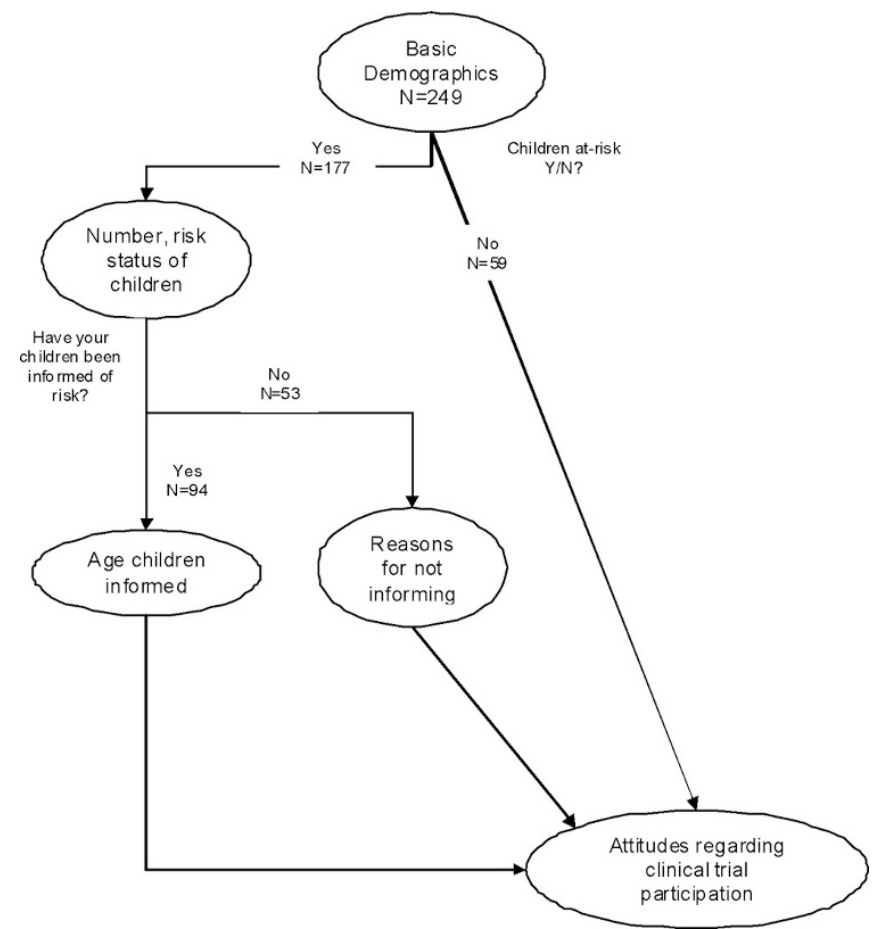

Fig. 1. Flow diagram illustrating forced aspect of the survey. All respondents provided basic demographic information regarding themselves. If they had no children, they completed the survey by indicating their attitudes regarding HD clinical research in adults in children. In respondents with children, information was obtained regarding the ages and risk status of their children. Parents who had informed their children were directed to questions relating to when the information was provided, while those who had yet to inform their children were probed for why they had not, and when they thought it appropriate to tell there children about HD. Each of these groups was then directed to the questions relating to HD clinical research.

Respondents with at-risk children who had informed their children of HD were subsequently directed to a series of questions relating to the age at which their children were informed, and the respondents' perception of how their children accepted the information. These respondents were then directed to the final series of questions. Those respondents who had not yet informed their at-risk children were queried about their reasons, and subsequently directed to the final series of questions.

The dataset was downloaded into Microsoft ${ }^{\circledR}$ Excel, enabling review of free text entries for all questions. The dataset was imported into $\mathrm{SAS}^{\circledR}$ for subsequent statistical analysis.

\section{RESULTS}

\section{Demographics}

The dataset indicated that 251 individuals accessed the survey from May 25, 2007 until October 23, 2007. Two respondents entered no responses for any questions, and thus are not included. Among the remaining 249 respondents, 193 completed the survey as defined by answering some or all of the final questions, giving a response rate of $77.5 \%$. The gender distribution of respondents was $80.9 \%$ female and $19.1 \%$ male ( $n=195$ female, $n=46$ male, and 8 blank responses). The average age of respondents was 42 years $(\mathrm{SEM}=0.8$, range 19-76), with 6 blank responses. Among females, the average age was 40.6 years $(\mathrm{SEM}=0.9)$ and for males was 48 years $(\mathrm{SEM}=2)$. Gene status of respondents was specified as negative or no risk (NEG) in $41.8 \%(n=104)$, at-risk for HD (AR) in $37.4 \%(n=93)$, gene positive but asymptomatic (ASYMPT) in $8.8 \%(n=22)$, gene positive and symptomatic (SYMPT) in $9.6 \%(n=24)$, or "other" in $2.4 \%(n=6)$. Comments from those who responded "other" indicated that these were individuals who had been tested for HD but found to have an indeterminate gene expansion, or those with unclear family histories. For subsequent analyses, the "other" group was omitted.

There was a relatively uniform distribution of respondents from the United States, with $23.7 \%$ reporting a residence in the Northeast, $28.5 \%$ in the South, $21.3 \%$ the Midwest, and $20.9 \%$ the West. Canadian and European respondents made up 2.8\% each. In terms of educational attainment of the respondents, $18.1 \%$ had completed some postgraduate education, with $34.9 \%$ being college graduates, $28.5 \%$ having some college, $14.9 \%$ high school graduates, and $2.8 \%$ with some high school.

Respondents were queried as to prior participation in clinical research. Of 249 respondents, $15.9 \%$ indicated that they had been involved in HD clinical research in the past or were currently enrolled in studies, whereas $84.1 \%$ had never participated in a clinical trial involving HD.

\section{Respondents and children}

Respondents were queried as to whether or not they had children at-risk for HD. Seven respondents failed to answer this question, but $51.3 \%(n=121)$ reported children at definite risk, while $25 \%(n=59)$ had no children. There were $23.7 \%$ $(n=56)$ who were unsure of risk status in their children.

Table 1 is a depiction of respondents who reported whether or not they had children, and indicated a response to the question "Have you or any family member informed your child or any of your children about Huntington disease, with reference to your children's genetic risk?" stratified by gene status. Fourteen percent of respondents with no risk (NEG) were childless, and $72 \%$ of parents had provided some information to their children. In comparison, $34 \%$ of AR, $21 \%$ of SYMPT, and $38 \%$ of ASYMPT reported no children. The percentages of respondents in each group who had provided information about HD to their children was $48 \%, 79 \%$, and $62 \%$ for AR, SYMPT, and ASYMPT groups, respectively. Interestingly, $26 \%$ and $7.7 \%$ of SYMPT and ASYMPT parents indicated that "I do not know if any of my children have a risk for HD," despite the fact that biological children would be assumed to carry a 50\% risk of the disease.

Respondents identified as parents were asked to provide information regarding number and ages of their children. Identified by birth year, 225 children were captured by these responses, with an average age of 11 years (birth year $=1996 \pm$ $0.36)$. Of this group, 217 could be correlated with gene status of the respondents, with $36.9 \%(n=80)$ of children having an at-risk parent, $40.1 \%(n=87)$ a gene negative parent, $12 \%$ $(n=26)$ a symptomatic parent, and $11.1 \%(n=24)$ a gene- 
Table 1

Respondents with children at risk for $\mathrm{HD}$, and patterns of informing children

\begin{tabular}{|c|c|c|c|c|c|c|c|}
\hline \multicolumn{2}{|c|}{ Respondent gene status } & \multicolumn{2}{|c|}{ Respondents with children at risk ${ }^{a}$} & \multicolumn{2}{|c|}{$\begin{array}{l}\text { Respondents who informed } \\
\text { children }^{b}\end{array}$} & \multirow{2}{*}{\multicolumn{2}{|c|}{ Summary }} \\
\hline & Number & & Number $\left(\%^{c}\right)$ & & Number & & \\
\hline \multirow[t]{7}{*}{ NEG } & 104 & Yes & $70(83.3)$ & Yes & 44 & No children & $14 \%$ \\
\hline & & & & No & 11 & Children & $86 \%$ \\
\hline & & & & Don’t know & 1 & $\%$ informed & $72 \%$ \\
\hline & & Unsure & $14(16.7)$ & Yes & 5 & & \\
\hline & & & & No & 7 & & \\
\hline & & & & Don’t know & 0 & & \\
\hline & & No children & 14 & & & & \\
\hline \multirow[t]{7}{*}{ AR } & 93 & Yes & $25(40.9)$ & Yes & 14 & No children & $34 \%$ \\
\hline & & & & No & 9 & Children & $66 \%$ \\
\hline & & & & Don’t know & 1 & $\%$ informed & $48 \%$ \\
\hline & & Unsure & $36(59)$ & Yes & 12 & & \\
\hline & & & & No & 17 & & \\
\hline & & & & Don’t know & 1 & & \\
\hline & & No children & 32 & & & & \\
\hline \multirow[t]{7}{*}{ SYMPT } & 24 & Yes & $14(73)$ & Yes & 10 & No children & $21 \%$ \\
\hline & & & & No & 3 & Children & $79 \%$ \\
\hline & & & & Don't know & 0 & $\%$ informed & $76 \%$ \\
\hline & & Unsure & $5(26)$ & Yes & 3 & & \\
\hline & & & & No & 0 & & \\
\hline & & & & Don't know & 1 & & \\
\hline & & No children & 5 & & & & \\
\hline \multirow[t]{7}{*}{ ASYMPT } & 22 & Yes & $12(92.3)$ & Yes & 6 & No children & $38 \%$ \\
\hline & & & & No & 6 & Children & $62 \%$ \\
\hline & & & & Don't know & 0 & $\%$ informed & $50 \%$ \\
\hline & & Unsure & $1(7.7)$ & Yes & 0 & & \\
\hline & & & & No & 0 & & \\
\hline & & & & Don't know & 0 & & \\
\hline & & No children & 8 & & & & \\
\hline
\end{tabular}

\footnotetext{
${ }^{a}$ Respondents indicated risk status for their children as "Yes" if they indicated "I have children who carry a risk for HD," or "Unsure" if they responded "I do not know if any of my children have a risk for HD." "No" refers to respondents who reported that they were childless.

${ }^{b}$ Column indicates if the response to the question "Have you or any family member informed your child or any of your children about Huntington disease, with reference to your children's genetic risk?" Responses were either "Yes," "No," or "Don't know."

'Numbers in parentheses indicate either the percentage of children reported as having definite (Yes) or uncertain (Unsure) risk for HD within groups stratified by respondent gene status.

NEG, negative or no risk; AR, at-risk; SYMPT, gene positive and symptomatic; ASYMPT, gene positive but asymptomatic.
}

positive, asymptomatic respondent. The average of the birth years of children with a NEG parent was $1994 \pm 0.5$ (13 years old), an AR parent was $1998 \pm 0.6$ (9 years old), SYMPT was $1995 \pm 1$ ( 12 years old), and ASYMPT was $1997 \pm 1.2$ (10 years old). Additionally, children could be identified by gene status $(n=285)$ in some cases with no birth year provided. The distribution was as follows: affected children, 9.8\% $(n=28)$; $50 \%$ risk, $51.6 \%(n=147) ; 25 \%$ risk, $7.7 \%(n=22)$; unknown risk, $30.9 \%(n=88)$. When stratified for respondent gene status, $62.8 \%$ of $50 \%$ risk children were reported by gene-negative respondents, and $68.2 \%$ of children with an unknown risk were reported by AR respondents.

\section{Information provided to children}

All respondents who reported having children were queried as to whether or not they had informed their children of HD. 
Of this group, 151 of 177 parents with children responded to the question, and $62.3 \%(n=94)$ indicated that some information had been provided to their children regarding HD risk. The average age of these parents was $47 \pm 0.9$ years. This response was stratified according to gene status, with NEG, AR, ASYMPT, and SYMPT reporting $72 \%, 48 \%, 62 \%$, and $76 \%$, respectively. There were 124 children identified who had been given information regarding HD, with a birth year of $1993 \pm$ 0.4 (14 years old). Among parents who had informed their children, the age at which they were informed was $12.2 \pm 0.5$ years.

Fifty-seven respondents (average age \pm SEM $=35.9 \pm 1$ ) reported that they had not yet informed their children. The gene status of respondents who had yet to inform their children was $\mathrm{AR}=47.3 \%, \mathrm{NEG}=34.5 \%$, $\mathrm{ASYMPT}=12.7 \%$, and SYMPT $=5.5 \%$. The average age of children not yet told $(n=$ 92) was 7 (birth age $=2000 \pm 0.5$ ). The chief reasons cited for not informing children were that their children were too young to understand in $64.2 \%$, and a desire to spare their children the distress of knowing about HD in $17 \%$. The individuals who had yet to inform their children felt that the most appropriate age to inform was $5-9$ years in $15.8 \%(n=9), 10-14$ years in $26.3 \%(n=15), 15-18$ years in $43.9 \%(n=25)$, and $14 \%$ would wait until adulthood $(n=8)$.

\section{Attitudes toward research and childhood participation}

To complete the survey, all respondents were asked five questions regarding participation of adults and children in clinical research addressing HD, regardless of whether they had children or not. Answers were scored on a 5-point Likert-type scale, with answers of strongly agree, agree, neutral, disagree, and strongly disagree. Questions 1 and 2 asked about participation of affected and at-risk individuals in clinical research, and questions 3-5 assessed attitudes regarding childhood participation in clinical HD research (No. 3), participation involving a neurologic examination of the child (No. 4), and participation that would involve "DNA testing" of a child (No. 5). In addition, for each of the last three questions, respondents who indicated "strongly agree" or "agree" were asked the optimum age at which the proposed activity would be most appropriate, with the ranges being "less than 5 years," " $5-9$ years," " $10-14$ years," or "15-18 years." Responses are depicted in Table 2. Over $88 \%$ of respondents felt that it was important for symptomatic and at-risk adults to participate in HD clinical research. Over 75\% indicated the importance of unaffected family members' participation. The percentage of individuals indicating that they agreed or strongly agreed with the importance of children from HD families participating in clinical research was $55 \%$. The age that was identified as most suitable for participation was 15 to 18 years in $51 \%$, and 10 to 14 years in $29 \%$ of these respondents. The last two questions related to specific activities proposed for the COHORT study. Question 4 described participation in an observational study that included a yearly neurologic examination. Sixty-three percent agreed or strongly agreed with allowing their own children to participate, and again the age of participation was more heavily weighted toward older children, with $47.4 \%$ of those respondents indicating 15 to 18 years as the optimum ages, and $26.7 \%$ indicating 10 to 14 years. Finally, the last question of the survey group described participation of children but also the collection of blood samples for "DNA testing," with the understanding that no results would be reported back to the individual. Forty-nine percent of respondents agreed or strongly agreed with the statement, with $44.6 \%$ and $27.2 \%$ indicating that they should take place between 15 and 18 and 10-14 years of age, respectively.

Table 2

Assessment of attitudes regarding participation in HD clinical trials

\begin{tabular}{|c|c|c|c|c|c|c|c|c|}
\hline & Q1 & Q2 & Q3 & Age $(n=100)$ & Q4 & Age $(n=116)$ & Q5 & Age $(n=92)$ \\
\hline Strongly agree & $54.9 \%$ & $40.5 \%$ & $22.3 \%$ & $\begin{array}{l}5-9=20 \% ; 10-14=29 \% \\
\quad 15-18=51 \%\end{array}$ & $28.3 \%$ & $\begin{array}{l}5-9=25.9 \% ; 10-14=26.7 \% \\
\quad 15-18=47.4 \%\end{array}$ & $21.2 \%$ & $\begin{array}{l}5-9=28.3 \% ; 10-14=27.2 \% \\
\quad 15-18=44.6 \%\end{array}$ \\
\hline Agree & $34.9 \%$ & $35.9 \%$ & $32.6 \%$ & & $34.8 \%$ & & $27.5 \%$ & \\
\hline Neutral & $10.3 \%$ & $19.5 \%$ & $35.2 \%$ & & $25.1 \%$ & & $21.8 \%$ & \\
\hline Disagree & 0 & $4.1 \%$ & $7.8 \%$ & & $8 \%$ & & $20.7 \%$ & \\
\hline Strongly disagree & 0 & 0 & $2.1 \%$ & & $3.7 \%$ & & $8.8 \%$ & \\
\hline $\begin{array}{l}\text { Total } \\
\text { respondents }\end{array}$ & 195 & 195 & 193 & & 187 & & 193 & \\
\hline
\end{tabular}

All respondents were directed to a series of five questions relating to clinical trial participation (Q1-Q5). For questions 3-5, respondents indicating strongly agree or agree were asked to give the optimum range in years for participation.

The following are the text of the questions:

Q1: I think it is important for symptomatic and at-risk adults to participate in clinical research of Huntington Disease.

Q2: I think it is important for unaffected family members of HD families to participate in clinical research of HD.

Q3: I think it is important for children in HD families to participate in clinical research of HD.

Q4: I would allow my own children to participate in observational (not treatment) HD research that included a yearly neurological examination. (If you have no children, answer as if you were a parent.)

Q5: I would allow my children to participate in observational (not treatment) HD research that included the collection of a blood sample for DNA testing, even though I would not be informed of the result. 
Table 3

Attitudes to clinical research participation, stratified by respondent gene status

\begin{tabular}{|c|c|c|c|c|c|c|}
\hline Respondent gene status & Q1 & Q2 & Q3 & Q4 & Q5 & Total \\
\hline \multicolumn{7}{|l|}{ AR } \\
\hline Mean (SD) & $4.27(0.77)$ & $4.00(0.87)$ & $3.42(1.02)$ & $3.40(1.15)$ & $3.14(1.29)$ & $18.19(4.08)$ \\
\hline$N$ & 77 & 77 & 77 & 75 & 76 & 74 \\
\hline \multicolumn{7}{|l|}{ NEG } \\
\hline Mean (SD) & $4.54(0.57)$ & $4.26(0.80)$ & $3.86(0.89)$ & $4.04(0.94)$ & $3.42(1.16)$ & $20.11(3.26)$ \\
\hline$N$ & 78 & 78 & 76 & 74 & 77 & 73 \\
\hline \multicolumn{7}{|l|}{ SYMPT } \\
\hline Mean (SD) & $4.65(0.70)$ & $4.29(0.92)$ & $3.88(0.86)$ & $4.06(0.85)$ & $3.53(1.42)$ & $20.19(3.69)$ \\
\hline$N$ & 17 & 17 & 17 & 16 & 17 & 16 \\
\hline \multicolumn{7}{|l|}{ ASYMPT } \\
\hline Mean (SD) & $4.50(0.69)$ & $3.90(1.02)$ & $3.50(1.10)$ & $3.84(1.01)$ & $3.50(1.28)$ & $19.16(4.29)$ \\
\hline$N$ & 20 & 20 & 20 & 19 & 20 & 19 \\
\hline$F$ & 2.78 & 1.81 & 2.99 & 5.35 & 0.94 & 3.57 \\
\hline$P$ & 0.0422 & 0.1473 & 0.0323 & 0.0015 & 0.4218 & 0.0153 \\
\hline
\end{tabular}

The text of each question is given in the footnote of Table 2 .

AR, at-risk; NEG, negative or no risk; SYMPT, gene positive and symptomatic; ASYMPT, gene positive but asymptomatic.

The internal consistency reliability of this 5-item scale was sufficiently high with a Cronbach's alpha of 0.84 . One-way analyses of variance (ANOVAs) were performed to evaluate whether the gene status groups differed in their responses to the 5-item scale and its total score. Table 3 shows the means and standard deviations (SD) for the responses to the questions and the total score for each gene status group. There is a statistically significant difference in these groups for the total score with the NEG and SYMPT groups responding in a very similar fashion while the ASYMPT and AR groups have lower total score means. There are also significant differences on questions 1 and 3 reflecting this same trend. The largest difference is on question 4 with the AR group responding the lowest indicating that they would be less likely to allow their own children to participate in observational HD research that included a yearly neurological examination.

Finally, respondents were given an opportunity to report their concerns for themselves and children should they participate in clinical trial initiatives. Potential issues were listed, and multiple selections for each question were acceptable. Tables 4 and 5 illustrate the prevalent responses. Among adults, regarding themselves, the chief concern was that of their participation having an effect on insurance. This was endorsed by three quarters of respondents. In children, over three quarters of respondents were concerned about negative psychological effects on a child, and two thirds that there would be potentially compromising information divulged to an insurance company. Also, over $50 \%$ were concerned about the child's understanding of the study, and the effect that participation would have on the child's understanding of HD.

\section{DISCUSSION}

Childhood participation in genetic research of a late onset disease will require a number of safeguards. Issues of consent and assent have been examined, and a number of recommendations have been accepted as necessary requirements to ensure ethical conduct of research. ${ }^{10,11,15-17}$ The COHORT study is one of a few large scale genetic research initiatives directed at a particular disease, and given the late onset of the disorder and the lack of any identifiable treatment, inclusion of children raises unique questions. What is clear, though, is that for chil-

Table 4

Concerns regarding participation in HD clinical research by adult respondents

Percent

\begin{tabular}{l}
\hline $\begin{array}{l}\text { If I were to consider participation in a } \\
\text { clinical trial, I would have concerns } \\
\text { about the following: (Check all that } \\
\text { apply) }\end{array}$ \\
$\begin{array}{l}\text { That my insurance could be affected } \\
\text { Whether or not I would receive the } \\
\quad \text { results of any testing }\end{array}$ \\
$\begin{array}{l}\text { That my job would be affected } \\
\text { Whether I would be told if I had HD or } \\
\text { not }\end{array}$ \\
$\begin{array}{l}\text { That people might find out that I am a } \\
\text { subject in an HD trial }\end{array}$ \\
$\begin{array}{l}\text { Other } \\
\text { Total answering question }\end{array}$ \\
\end{tabular}


Table 5

Concerns of respondents regarding childhood participation in HD clinical trials

\begin{tabular}{lc}
\hline & Percent \\
\hline $\begin{array}{l}\text { If my child was to participate in an HD study, } \\
\text { I would be concerned about the } \\
\text { following: (Check all that apply, and if } \\
\text { you are childless, answer as if you were a } \\
\text { parent) }\end{array}$ & \\
If participation would have any negative & $78.2 \%(n=147)$ \\
psychological effects on my child & \\
That my insurance company would learn \\
that there is HD in my child's family \\
$\begin{array}{l}\text { How much my child understood about the } \\
\text { study }\end{array}$ \\
$\begin{array}{l}\text { What effect that participation would have } \\
\text { on my child's understanding of HD }\end{array}$ \\
$\begin{array}{l}\text { That other family members would find out } \\
\text { Total answering question }\end{array}$ \\
\hline
\end{tabular}

dren to participate in COHORT, they must have knowledge of the purpose and consequences of their taking part in such a clinical trial. Moreover, given their status as a "vulnerable population," children must not be subjected to the risk of harm by participation.

One of the primary goals for this study was to obtain data that would help to clarify the issues relating to recruitment of unaffected children in the COHORT study. Chief among these unknowns was an assessment of practices of families with HD of informing children of the disease. In addition, general attitudes toward clinical research were also important to ascertain, particularly as they relate to study activities in operation in COHORT. The application of an ethical pilot study was felt to be a reasonable first step, given that confidentiality could be preserved, and there was a potential for obtaining a large sample or respondents. Prior studies using ethnographic methodology have demonstrable benefit as they have informed clinical trial design, as well as illustrating educational requirements. ${ }^{14,15}$ However, comprehensive surveys of parental attitudes toward genetic research involving children remain preliminary, and standardized recommendations do not yet exist. Currently, a large genetic-epidemiologic study is under consideration by the NHGRI which would include 120,000 children, and involve health-related assessments, as well as donation to a biobank. Comprehensive genotyping would be performed to investigate the interplay of environment and genetics in childhood diseases. To date, focus groups have been convened to assess parental attitudes regarding such a study, and have identified major themes of assent, risks and benefits to children, confidentiality, and the return of pertinent results to parents. ${ }^{13}$ Although similar in concept to the present study, our focus on $\mathrm{HD}$ is unique, as the overriding purpose is to ultimately aid in the development of a cure for the disease. Therefore, although COHORT is primarily an observational study, it has the potential in itself to inform the development of treatment trials for HD.

\section{Respondent demographics}

Women outnumbered men approximately 4:1 in terms of participation, and gender bias has also been observed in other HD studies, ${ }^{18}$ but have focused primarily on adult recruitment. Women at risk for HD are reported to be more willing to share information regarding their genetic status, ${ }^{19}$ and this could contribute to the predominance of female respondents. The fact that the present survey deals with childhood participation in a clinical trial would suggest that the importance of this issue to mothers of children in families with HD. Although perhaps an obvious conclusion, it does point toward the significant role that mothers will play for childhood participants in discussions regarding the acceptability of the study.

Besides a gender bias, there was an age discrepancy in respondents when stratified according to gene status. The NEG group was the oldest (average \pm SEM $=48 \pm 1.2$ years), and this group in all likelihood reflects a population of caregivers. Distinct from that are the ages of respondents who were AR or ASYMPT, at $36 \pm 1.0$ and $36 \pm 2.4$ years, respectively. This is certainly consistent with the natural history of $\mathrm{HD}$, as the average age of these groups is at the lower range when HD typically begins to manifest itself clinically. Again, this demographic is significant, as it represents an identifiable segment of HD family members with concerns about childhood participation in clinical trials.

Finally, this group represents one that is overwhelmingly naive to clinical trial participation with respect to $\mathrm{HD}$, with $85 \%$ indicating no history of inclusion in an HD study. This is not particularly surprising, given that the majority of prior HD studies have focused on gene positive individuals who were either presymptomatic or symptomatic. Nevertheless, the attitudes of this population are of significance given that this group is targeted for enrollment in COHORT, and further demonstrate the need for appropriate education of potential subjects.

\section{Children in HD families}

Almost 75\% of the respondents to the study indicated that they had children. Over two thirds of parents were aware of a specific risk status for their children; nearly one third were uncertain of their children's risk. Inability to assign childhood risk could certainly be related to the fact that many AR individuals are uncertain of their own status. Indeed, the AR group was the only one indicating uncertainty of risk status in over one half of their reported children. However, in the gene positive groups, $26.7 \%$ of SYMPT and $7.7 \%$ of ASYMPT respondents were uncertain of their children's risk status. This suggests a significant need for education in light of the fact that $\mathrm{HD}$ is dominantly inherited. In terms of the frequency of respondents with no children, over one third of the AR and ASYMPT groups had no children, whereas $14.2 \%$ of NEG and $20.8 \%$ of SYMPT respondents were childless. Given that the NEG and SYMPT groups had a higher mean age than the AR 
and ASYMPT respondents, this may only be an indication that the latter two groups have simply not yet begun their families, but will require further study to better understand.

Questions regarding whether information about HD has been shared with children provided some fairly telling results. Approximately two thirds of respondents had informed their children of some type of risk related to HD. The average age of respondents who had told her children was 47 , and the average age of this group of children at the time of this survey was about 14. These children were informed of their status at approximately 12 years of age. In contrast, of the one third of children who had not been told, the average age of the parent at the time of the survey was 36, and the average age of the children was 7 years. Overall, parents responding to the survey who were NEG tended to have older children, and were more likely to have informed their children of HD. On the other hand, AR parents were younger, had younger children, and in fewer than half had not yet informed their children. These data suggest that older families with older children will be more likely to provide informed consent and assent.

Children who had not been informed were younger, with a birth year of 2000 (7 years old). The most common reason cited for not telling children was due to young age. The majority of parents who had not yet told their children of HD anticipated that they would tell their children between 15 and 18 years of age. Whether or not this number will decrease if and when parents become symptomatic is uncertain, but a future line of investigation will be to try and assess how parents identify the ages at which they tell their children, and why children who have been informed received their information at a younger age than the stated preference of 15-18 years.

\section{Participation in clinical research}

Respondents completed the survey by answering general questions regarding clinical research. By combining supportive responses (strongly agree and agree), large majorities indicated the importance of adult participation in HD studies, with $88 \%$ supporting gene-positive and at-risk involvement, and $75 \%$ supporting unaffected family member participation. This is an impressive majority, especially given that few respondents have ever participated in HD research, and indicates a strong willingness to take part in research initiatives. Statistically, though, when stratified by gene status, there is a tendency for lower scores in the AR and ASYMPT groups, indicating less support than the NEG and SYMPT groups. However, the mean scores still indicate support from all groups with respect to participation of adults.

Approximately, 55\% of respondents supported children in HD families as participants in clinical research, with over half indicating that the most appropriate age for inclusion to take place as 15-18 years, suggesting that recruitment to COHORT will be most acceptable in the adolescent age group. This age range coincides with the age at which parents who have not yet informed their children expect to tell them of HD, but is older than the age that most children who were identified as already being informed of the disease. The lowest scores (least agree- ment) was seen in the AR and ASYMPT groups, with statistical significance when compared with NEG and SYMPT respondents. This discrepancy bears further study, but the responses at the very least indicate the support for inclusion of adolescents in HD clinical research. To ethically recruit such children, the requirements for assent to participate could only be satisfied if children had sufficient knowledge of the disease, and the responses in this survey would suggest the suitability of older adolescents as potential research subjects. Additionally, the difference in responses when stratified for gene status is informative for COHORT, as it could signify the relative unwillingness of AR and ASYMPT parents to allow their children to participate. The possible reasons for this are not clear from this survey, though, and will require more study.

Questions 4 and 5 attempted to probe for attitudes of respondents regarding a yearly neurologic examination and collection of a blood sample for "DNA testing," study activities considered for COHORT. A yearly neurologic examination was supported by $63 \%$ of respondents, and blood collection was supported by almost $49 \%$, with the optimum age for these activities at $15-18$ years in $51 \%$ and $47 \%$, respectively. In question 5, "DNA testing" was not defined, but it is customary for most clinical trials involving HD to include the donation of a blood specimen for genotype analysis, and for any results to not be reported back to the individual. Although this is a common practice in adult clinical trials, there may be a need for greater education and sensitivity in COHORT with respect to this activity should children be included. Indeed, there may be a more nuanced understanding of "DNA analysis," but this will bear further investigation. Statistical analysis again revealed significantly lower scores among the AR and ASYMPT groups when compared with the NEG and SYMPT groups, with the former two groups least amenable to a yearly neurologic examination. Given that an abnormal neurologic examination of the child of an AR individual would be informative to extent that it would likely guarantee an ultimate diagnosis in the parent, some care must be taken by clinical investigators to be cognizant of these concerns.

Respondents' concerns for themselves and their children regarding participation in HD clinical research included issues of confidentiality (adults and children) and the psychological impact on a child. Interestingly, these are among key issues relating to participation in genetic studies as identified by more traditional ethnographic methods. ${ }^{13}$ These concerns as raised by parents indicate a number of issues that will need to be addressed with regard to the assent and informed consent process, as well as study design of the COHORT study. In addition, further investigations are needed to further understand the possibility of the negative psychological impact on children who participate in HD clinical research.

There are certain limitations to the present study. The use of an Internet survey may be called into question, because of the lack of any type of face-to-face interaction, and an inability to obtain more nuanced information. ${ }^{20}$ On the other hand, an anonymous survey enabled the acquisition of information from people who might not normally be approached in any 
other fashion. In addition, it is significant that the major concerns endorsed by parents regarding childhood participation (confidentiality, psychological impact, etc.) are identical to those concerns developed in a focus group setting. ${ }^{14}$ There are clear restrictions, however, on what type of information can be obtained from this type of survey. Although parents indicated that they had provided some type of information to children about HD, the quality and depth of the imparted knowledge cannot reliably be assessed. Nevertheless, this study has opened up a number of potential lines for investigation. Thoroughly understanding how children are told, and indeed, what they are told, will be a requirement that must be satisfied if any widespread enrollment of minors in any type of HD clinical trial. Ethnographic techniques will need to be employed in targeted populations to better understand how information is transmitted from parent to child, in the context of a disease such as HD. We believe that this pilot has served not only to inform the COHORT study of a roadmap toward the eventual inclusion of children, but also served to highlight future research questions that can be directed at this population.

\section{ACKNOWLEDGMENTS}

The consultation was provided as a service of the Rapid Ethics Action Consult Team (REACT), and is supported by NHGRI award P50-HG003390.

The authors thank the Huntington Study Group, in particular the Steering Committee of the Cooperative Huntington Observational Research Trial (COHORT) for their helpful comments, and also acknowledge Mark Aulisio, MD and Jessica Berg, JD, of the Center for Genetics Research Ethics and Law at Case Western Reserve University, who consulted on the survey design and the purpose of the study.

\section{References}

1. Leegwater-Kim J, Cha JH. The paradigm of Huntington's disease: therapeutic opportunities in neurodegeneration. NeuroRx 2004;1:128-138.
2. Julien CL, Thompson JC, Wild S, et al. Psychiatric disorders in preclinical Huntington's disease. J Neurol Neurosurg Psychiatry 2007;78:939-943.

3. Rosenblatt A. Understanding the psychiatric prodrome of Huntington disease J Neurol Neurosurg Psychiatry 2007;78:913.

4. Paulsen JS, Langbehn DR, Stout JC, et al. Detection of Huntington's disease decades before diagnosis: The Predict HD study. J Neurol Neurosurg Psychiatry 2008;79:874-880.

5. Berrios GE, Wagle AC, Markova IS, et al. Psychiatric symptoms and CAG repeats in neurologically asymptomatic Huntington's disease gene carriers. Psychiatry Res 2001;102:217-225.

6. Huntington Study Group. Dosage effects of riluzole in Huntington's disease: a multicenter placebo-controlled study. Neurology 2003;61:1551-1556.

7. Huntington Study Group. A randomized, placebo-controlled trial of coenzyme Q10 and remacemide in Huntington's disease. Neurology 2001;57:397-404.

8. Berrios GE, Wagle AC, Markova IS, Wagle SA, Rosser A, Hodges JR. Psychiatric symptoms in neurologically asymptomatic Huntington's disease gene carriers: a comparison with gene negative at risk subjects. Acta Psychiatr Scand 2002;105:224-230.

9. Informed consent, parental permission, and assent in pediatric practice. Committee on Bioethics, American Academy of Pediatrics. Pediatrics 1995;95:314-317.

10. De Lourdes Levy M, Larcher V, Kurz R. Informed consent/assent in children. Statement of the Ethics Working Group of the Confederation of European Specialists in Paediatrics (CESP). Eur J Pediatr 2003;162:629-633.

11. Rossi WC, Reynolds W, Nelson RM. Child assent and parental permission in pediatric research. Theor Med Bioeth 2003;24:131-148.

12. 45CFR46.408, 2007.

13. Kaufman D, Geller G, Leroy L, Murphy J, Scott J, Hudson K. Ethical implications of including children in a large biobank for genetic-epidemiologic research: a qualitative study of public opinion. Am J Med Genet C Semin Med Genet 2008;148:31-39.

14. Gillam L, Poulakis Z, Tobin S, Wake M. Enhancing the ethical conduct of genetic research: investigating views of parents on including their healthy children in a study on mild hearing loss. J Med Ethics 2006;32:537-541.

15. Brody JL, Scherer DG, Annett RD, Pearson-Bish M. Voluntary assent in biomedical research with adolescents: a comparison of parent and adolescent views. Ethics Behav 2003;13:79-95.

16. Gill D, Crawley FP, LoGiudice M, et al. Guidelines for informed consent in biomedical research involving paediatric populations as research participants. Eur J Pediatr 2003; 162:455-458.

17. Hurley JC, Underwood MK. Children's understanding of their research rights before and after debriefing: informed assent, confidentiality, and stopping participation. Child Dev 2002;73:132-143.

18. Hogarth P, Brocht A, Kayson E, Orme C, Zhao H, Shoulson I. Gender disparity in study participation among individuals at risk for Huntington's disease. Movement Disorders 2000;15:1042.

19. Taylor S. Gender differences in attitudes among those at risk for Huntington's disease. Genet Test 2005;9:152-157.

20. Gosling SD, Vazire S, Srivastava S, John OP. Should we trust web-based studies? A comparative analysis of six preconceptions about internet questionnaires. Am Psychol 2004;59:93-104. 